\title{
Operational Oil-Slick Characterization by SAR Imagery and Synergistic Data
}

\author{
Fanny Girard-Ardhuin, Member, IEEE, Grégoire Mercier, Member, IEEE, Fabrice Collard, and \\ René Garello, Senior Member, IEEE
}

\begin{abstract}
A methodology is proposed for the semiautomatic detection, characterization, and classification of slicks detected in C-band Synthetic Aperture Radar (SAR). For the first detection step, automatic algorithms were tested on Environmental Research Satellite (ERS) and Environmental Satellite (EnviSat) images acquired during the Prestige tanker accident. These tests reveal that simple filter or segmentation methods efficiently detect slicks with high contrasts and simple shapes, while a new and more complex multiscale method is able to detect a wider range of slicks. The characteristics of automatically detected slicks are then combined with meteooceanic data in order to eliminate slicks related to wind anomalies and current fronts. The data suggest that slicks in cold upwelling waters are natural, and confirm that slicks are heavy oils when high sea states are present. This detection-classification methodology is validated with aircraft slick-tracking maps. In most cases, joint SAR and environmental data are sufficient to classify the slicks.
\end{abstract}

Index Terms-Image analysis, oil pollution, satellite measurement, synthetic aperture radar (SAR).

\section{INTRODUCTION}

$\mathbf{O}$ CEAN pollution captured the headlines in 2002 with the Prestige accident off the Spanish coast, as it previously did during the Exxon Valdez, Erika, and Aegean Sea accidents; yet the vast majority of oil pollution occurs every day due to offshore operations and intentional discharges on important shipping routes, such as the Mediterranean, the Baltic Seas, the Atlantic Ocean, and the Malacca Strait.

Surface slicks can also be natural, of either biological (made by photooxidation, bacterial decomposition, and other plankton

Manuscript received October 29, 2004; revised March 21, 2005; accepted June 17, 2005. This work was supported in part by the MARine Synthetic aperture radar Analysis and Interpretation System (MARSAIS) program, which is funded by the Fifth Framework Program in CEC (contract EVG2-2000-00521). Multiscale oil-slick segmentation was supported by Groupe des Ecoles de Télécommunications (GET) with the GET-RE-315 contract. Associate Editor: R. Romeiser.

F. Girard-Ardhuin was with the Groupe des Ecoles de Télécommunications (GET)-École Nationale Supérieure des Télécommunications de Bretagne (ENSTB), 29238 Brest, France and also with Brest Operational Observation Systems and Technologies (BOOST), Plouzané 29280, France. She is now with Institut Français de Recherche pour l'Exploitation de la MER (IFREMER), Plouzané 29280, France (e-mail: fanny.ardhuin@ifremer.fr).

G. Mercier and R. Garello are with Groupe des Ecoles de Télécommunications (GET)-École Nationale Supérieure des Télécommunications de Bretagne (ENSTB), Brest 29238, France (e-mail: gregoire.mercier@enst-bretagne.fr; rene.garello@enst-bretagne.fr).

F. Collard is with Brest Operational Observation Systems and Technologies (BOOST), Plouzané 29280, France (e-mail: fabrice.collard@boost-technologies.com).

Digital Object Identifier 10.1109/JOE.2005.857526 and fish releases) or of geological origin (deep-sea-floor seeps). It is estimated that $10 \%$ of the ocean surface is covered by natural slicks or oil spills.

Slick detection is relevant for many applications. Slicks must be taken into account in climate-change models since they act as a natural barrier against sea/air fluxes [1]-[3]. Moreover, in order to fight illegal discharges and in the case of accidents, we need to know precisely where polluted areas are and their drift has to be estimated in order to protect coastal zones. This can be done locally by airborne survey, but satellites are useful for monitoring surface pollution, thanks to their regular passes over an ocean area [4]-[8]. Slicks are observed on seas all over the world and half of the satellite images present at least one dark patch, like that in the Mediterranean Sea [statistics on 1600 synthetic aperture radar (SAR) Environmental Research Satellite (ERS) images in [5]], the Baltic sea [8], and the southeast Asiatic area [4].

For all these reasons, efficient slick detection means have been implemented with airborne and satellite measurements. Nevertheless, the use of external data is necessary to assess slick classification. The purpose of this paper is to underline a methodology for using SAR data in conjunction with external data for oil-slick classification in an operational context.

Satellite remote-sensing detection is well adapted since it produces images regularly in difficult access areas. Several kinds of measurements have been tested: optical, infrared, and radars with different frequencies. SAR seems to be one of the most suitable instruments among satellite sensors for this kind of application since it does not depend on weather (clouds) or sunshine. It makes it possible to show illegal discharges that appear most frequently during the night; it can also survey storm areas, where accident risks are increased. Added to local aircraft tracking, SAR could be helpful for synoptic oil-spill monitoring. Its spatial coverage can be as wide as $500 \times 500 \mathrm{~km}$ and, moreover, it can produce high-resolution images (up to about $10 \mathrm{~m}$ ).

This paper is organized as follows. Section II will present a short synthesis of the most suitable radar-acquisition configuration and the influence of meteooceanic conditions on surface detection. Section III will develop SAR image-analysis steps, highlighting the importance of the two steps: detection and classification. Sections IV and V will illustrate the importance of these two steps by using the case of the Prestige tanker accident. Four detection algorithms will be applied to highlight the difficulty of detection on complex images. This will be completed by a classification step, using the knowledge of meteooceanic data in order to draw conclusions about the nature of the detected film. Section IV focuses on the emergency context of the 
Prestige accident, while Section V is dedicated to routine classification after the accident. In conclusion (Section VI), a methodology to apply in an operational context will be proposed and discussed.

\section{SLICK DETECTION}

\section{A. Effect of Slicks on the Ocean Surface}

Franklin was among the first modern scientist to be interested in the applications of wave damping by surface slicks [9]. This effect was used to save boats during storms by leaking oil to break the waves, notably by the US, English, and French Navies [2], [3].

A slick at the ocean surface damps gravity-capillary waves as explained by Marangoni's theory, which is detailed in [10]-[16]. Wave damping is due to the decrease in surface stress, which is associated with film elasticity, and also to the slick nature, density, and surface viscosity.

\section{B. Influence of Parameters on Slick Radar Measurement}

Radar is sensitive to surface roughness, which are linked by gravity-capillary waves and damped by slicks. The radar backscattering level is decreased by the presence of a slick, which appears as dark patch with weak backscattering in comparison with the surrounding regions in a radar image.

From a synthesis of previous experimental studies, the best approach to take in detecting slicks is to consider a function of several parameters, such as radar configuration, slick nature (natural slick or oil spill), and meteorological and oceanic conditions.

1) Wavelength: Each radar frequency band responds differently, according to wind speed and slick nature [15]-[19]. Several experimental multifrequency studies have shown the greatest contrast with $\mathrm{C}-$, $\mathrm{X}-$, and $\mathrm{Ku}$-bands by using artificial slicks (MARSEN79, SAXON FPN, SAMPLEX92) [17], [20], [21]. There is about a 5-dB contrast for a slick made with "light" fuel, and a 10-15-dB contrast for "heavy" fuel [17], [22]. Wave numbers less than $80 \mathrm{~m}^{-1}$ (L- and S-bands) are weakly affected by slicks. This has been shown experimentally and with numerical simulations [17], [20], [21], [23], [24].

Strong winds are a real problem for the damping measurement. The C-band frequency seems to be the most suitable frequency, allowing strong contrasts to be measured up to a wind speed of about 10 to $14 \mathrm{~m} \cdot \mathrm{s}^{-1}$ [18]. Contrasts are observed among slicks as a function of sea-state conditions: from 6 to $17 \mathrm{~dB}$ with ERS SAR $(5.3-\mathrm{GHz}$ frequency in the C-band) [25], [26].

2) Polarization: The choice of polarization depends on radar frequency and wind speed. Some experiments have shown that there is no real difference between horizontal $(\mathrm{HH})$ and vertical (VV) polarization for slick study [21]. However, VV polarization seems to be the most suitable for the C-band, notably for strong winds, which have speeds higher than 11 $\mathrm{m} \cdot \mathrm{s}^{-1}$ [27], [28].

3) Incidence Angle: The reflection mode of the incident electromagnetic wave is a function of the incidence angle. There are two backscattering mechanisms: a Kirchhoff, for a $0^{\circ}$ to $15^{\circ}$ incidence angle, and the Bragg reflection for a $20^{\circ}$ to $70^{\circ}$ incidence angle. The latter allows observation via Bragg resonance with gravity-capillary waves that are highly damped by surface films. The backscattering reflection coefficient decreases as the incidence angle increases [29], [30]. However, it is also a function of wind speed [22]: theoretical damping for a slick is about $5 \mathrm{~dB}$ for low wind speeds and 3-4 dB for $10-\mathrm{m} \cdot \mathrm{s}^{-1}$ wind speeds when observed by ERS SAR with a $23^{\circ}$ incidence angle [27].

According to wind constraints and radar frequency, the most suitable incidence angle is from $20^{\circ}$ to $45^{\circ}$.

4) Angle Between Flight Direction and Wind Direction: For wind speeds higher than $9 \mathrm{~m} \cdot \mathrm{s}^{-1}$, this angle has to be taken into account, as shown by the experimental studies SAXON FPN and SAMPLEX92 [17]. Hühnerfuss et al. [15] shows that this angle has to be less than $30^{\circ}$ with L- and X-bands in order to keep a significant contrast among slicks.

5) Nature of the Slick: Backscatter damping is a function of the slick nature and of the slick properties of viscosity and elasticity [12], [23]. Wave damping is more important for oil spills than for natural slicks in the C-, X-, and Ku-bands [17], whereas natural slicks cause stronger damping with the L-band (for wind speeds lower than $8 \mathrm{~m} \cdot \mathrm{s}^{-1}$ [19]). Thus, the use of multifrequency radar measurements may play a role in determining slick nature [19].

Slick nature is also related to thickness: oil spills tend to be thicker than natural slicks; moreover, thickness is more important, with a 1-2-dB effect, at the oil-spill center [21], [22]. Thus another sensor, such as a light detection and ranging (lidar), is required to measure this parameter [31].

Temperature is also an interesting parameter because slicks induce surface-temperature change, which can be measured by infrared sensor, as shown in, e.g., [32].

Slick age is an important parameter to take into account, too. Radar waves do not penetrate the ocean surface, so this radarmeasurement limitation implies that slicks can only be detected if they are "new" slicks, because they are quickly submerged to a subsurface level, due to wave mixing.

Another way to distinguish the nature of the slick is to take into account slick shape and size. If slicks are long and straight, they are probably associated with ship discharges. Moreover, the shape of the slick itself evolves according to age, nature, internal waves, surface currents, wind, etc. Wind history can be added in slick study.

6) Influence of Meteorological and Oceanic Conditions: Some conditions produce similar features as oil spills on radar images (look-alike). For example, weak backscatter areas exist over weak wind regions, like in the lee of an island. Some other conditions, like oceanic internal waves, quickly distort slicks, which become less dense, thus, less easy to detect.

SAR measurements are limited by sea state, which are related to meteorological conditions. Efficient radar detection of surface films at the $\mathrm{C}$-band frequency requires wind speed from 2-3 $\mathrm{m} \cdot \mathrm{s}^{-1}$ to $10-14 \mathrm{~m} \cdot \mathrm{s}^{-1}$ [12], [27]. At lower wind speeds, the surface roughness is not uniform and the calmer areas look like oil spills: capillary waves are not created, radar backscattering remains low, and contrast becomes too weak. At higher wind speeds (up to 10-14 $\mathrm{m} \cdot \mathrm{s}^{-1}$ ), backscattering remains high in the slick and then contrast decreases. Moreover, surface slicks, 
and especially, natural films, may be submerged in subsurface waters by the strong turbulent mixing. Therefore, the slicks detected are unmistakably oil spills in such severe conditions.

The wind is the most important parameter in slick SAR imaging.

\section{SAR IMAGE ANALYSIS}

Fully automatic analysis of SAR images is not available for slick classification. In fact, most detection algorithms suffer from false alarms, and classifications may confuse with look-alikes.

Three basic steps, and an additional one, are needed for slick analysis from SAR images: 1) detection; 2) characterization; and 3) classification. The fourth step states that external data are required to improve slick analysis.

1) Detection: A film-covered area appears smoother than a clean sea surface since small-wave generation and propagation are reduced by the viscosity of a slick. From the SAR-sensor point of view, a slick is characterized by a lack of backscattered energy, and thus, shown as a dark area [33]. According to the Bragg scattering theory, the backscattering process is mostly due to surface roughness. That is why many film-detection algorithms are based on a thresholding technique [34]-[36].

A radiometric point of view shows some limitations, since wave slopes that are not oriented to the sensor are shown with a reduced radar backscatter that may be confused with the presence of slick. Then, postprocessing stages are included to remove small patches using geometrical, morphological, or contextual criteria [8], [37], [38].

2) Characterization: Detection algorithms yield the patch location of suspected pollution. Feature extraction is necessary to perform slick classification. For instance, illegal discharges are often associated with elongated straight slicks. That is why every detected area may be characterized by geometric parameters, such as shape, length, width, gradient, contrast between slick and neighborhood, averaged radiometry [8], [39], [40], etc.

3) Classification: Oil spills and look-alikes are classified into a feature-space representation. Statistical, fuzzy logic, and neural approaches have been applied [8], [39], [40]. A state of the art of slick detection and classification may be found in [41]. With a complete knowledge of near-realtime environmental and geographical data, Solberg et al. [8] show that an operational system can exist: with their system, $94 \%$ of cases are well analyzed by assigning a probability for a slick to be due to pollution.

In addition, it has been shown that the nature of a slick can be determined easily by using multifrequency radar [20]. Nevertheless, most radar measurements from satellites are performed by a single frequency. Since the observations do not acquire the total physical information, external data are needed to improve classification results and assess the slick nature.

4) Need for external data: Meteorological and oceanic conditions have to be taken into account. For instance, the knowledge of wind speed allows some hypothesis to be rejected: under $2 \mathrm{~m} \cdot \mathrm{s}^{-1}$, a weak backscattering area is more probably due to a lack of wind than to pollution. Beyond $10 \mathrm{~m} \cdot \mathrm{s}^{-1}$, each detected slick is probably an oil slick since turbulence mixes natural slicks in the subsurface level. Upwelling areas may be detected by sea-surface temperature maps. This may help the analysis in some cases.

Recently, wind-and-tidal-current history have been combined with SAR images in order to determine slick age and original shape.

An ERS SAR satellite survey was used, in addition to an airborne survey, during the Aegean Sea pollution in 1992 [42]. More recently, EnviSat Advanced SAR (ASAR) satellite images were analyzed during the Prestige disaster in 2002. These cases show that a major problem is the time necessary to deliver the images to experts for analysis and interpretation. Furthermore, semiautomatic algorithms would be helpful to experts in their analysis, but only a few of these have been validated.

\section{Application to Prestige Wreck}

\section{A. Case Study}

In 2002, the Prestige tanker accident off the Spanish coast was a major environmental disaster since a huge quantity of oil dumped in the ocean drifted over large distances. This example has been chosen for two main reasons. First, daily aircraft surveys were performed, giving maps of detected surface oil spills. Second, many images were acquired over the region during the oil-spill drift [the European Space Agency (ESA) provided EnviSat and ERS images over the area of the Prestige wreck for several months].

Therefore, basic and complex detection algorithms, and then, the classification technique of synergy, have been applied in the following.

\section{B. Detection Step}

Before applying any slick-detection algorithm, the backscatter image is calibrated and transformed into a sea-surfaceroughness image using an ocean-backscatter model such as CMOD [43]. This important step removes the incidence-angle dependence across the range, and thus, enables the estimation of global clean-water-image statistics that are used in most detection algorithms.

Four algorithms were implemented.

1) The first method is a succession of median and Sobel filters followed by a mathematical-morphology combination of dilatation and erosion.

2) The second one is also a simple algorithm that uses smoothing followed by thresholding and Sobel filters. This method is used for the Mediterranean Sea pollution detection by the Joint Research Center (JRC).

3) The third algorithm is a combination of gradient and attenuation relative to a background level estimated on a low-pass filtered image. A set of morphological filters is then used to connect neighboring slicks. The kernel size of each low pass, gradient, and morphological filters is adapted to the image-resolution-and-processing algorithm. This algorithm is used in the SARTool software of 


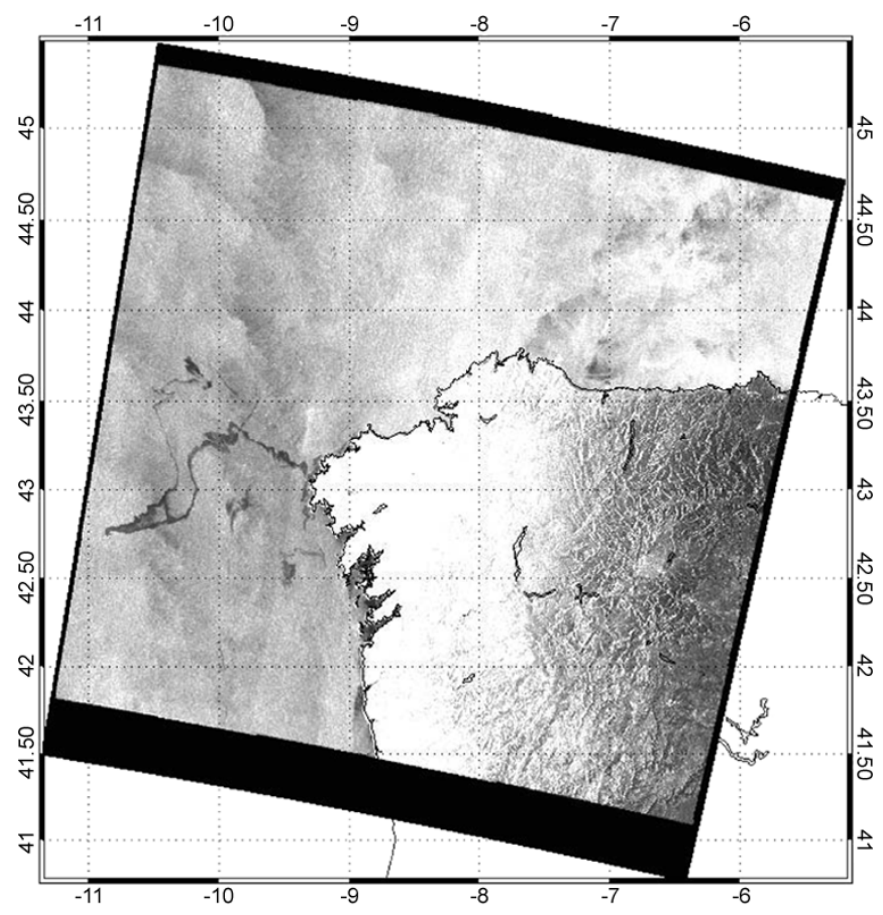

Fig. 1. EnviSat ASAR image, November 17, 2002, acquired at $10 \mathrm{~h} 45$ UTC (wide-swath mode, orbit 3741, polarization VV) off the Spanish coast, after the Prestige tanker started to be towed on November 13 ESA.

Brest Operational Observation Systems and Technologies (BOOST).

4) The last method is a complex algorithm of ocean-surface characterization, developed at Ecole Nationale Supérieure des Télécommunications de Bretagne (ENST Bretagne). It is based on a multiscale analysis of the observed data that stresses the different shapes of the sea-surface wave spectrum on clean and polluted water [44].

\section{Analysis of SAR Image}

The overall study is based on several areas of SAR images, but only a small example is illustrated in this paper. A part of an ASAR EnviSat image acquired on November 17, 2002 near the Spanish coast is analyzed (Fig. 1). This image was acquired 4 days after the Prestige tanker started to be towed and 2 days before it sank. Dark patches are visible from the tanker over an area of about a hundred kilometers. This case is very interesting for testing segmentation methods because of the ambiguities in the interpretation of the study area [Fig. 2(a)] due to the large area covered by slicks, which can be associated with different sea states. Moreover, the atmospheric and sea-state conditions made local in situ sea-state measurements difficult.

The Prestige tanker appears as a bright spot southwest of the slick [Fig. 2(a)]. From this point, two polluted "arms" drift towards the north and east, probably caused by the spread of two kinds of oil mixed in the tanker, as experts said after sampling (see [45]; the analysis of the fuel can also be found in [46]). Although the oil spill is clearly defined around the tanker, the drift part is more complex. Radar backscatter is influenced by the properties of oil, but it is not possible to conclude that these "arms" appear on the radar image with a different contrast. One (to the north) presents a strong contrast for its north boundary,
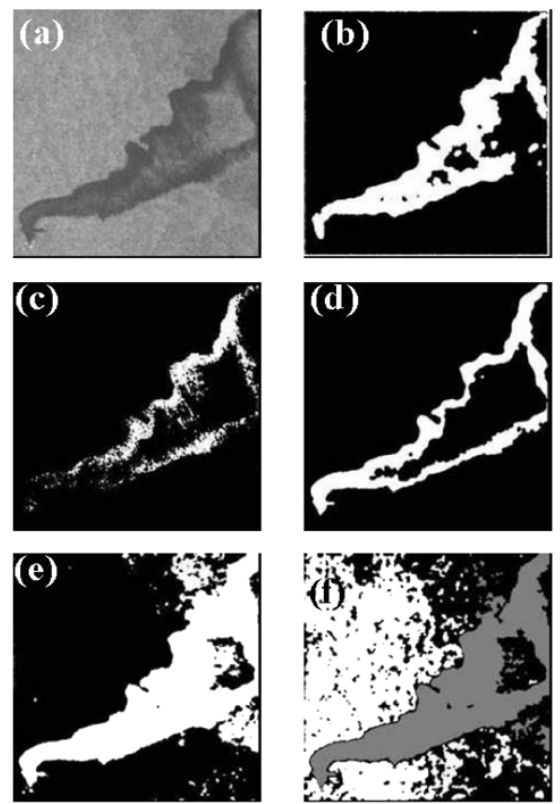

Fig. 2. a) Study area extracted from Fig. 1 (size: $38 \mathrm{~km} \times 38 \mathrm{~km}$ ). Analysis of (a) with methods described in Section IV-B: (b) method 1, (c) method 2, (d) method 3, (e) method 4 with two classes, and (f) method 4 with three classes (Image courtesy of ESA).

whereas the second (to the south) is not so clearly defined and seems to have started being submerged.

The algorithms mentioned above were applied over this study area [Fig. 2(b) to (f)]. Method 2 is not efficient for this image: Fig. 2(c) presents blurred slick boundaries and no pollution near the tanker is found. Methods 1 and 3 highlight top-and-bottom oil-spill outlines and show a nonpolluted area in the middle of the two principal polluted "arms." This area is smaller with method 1 [Fig. 2(b)] than with method 3 [Fig. 2(d)]. Method 4 applied with two classes [Fig. 2(e)] presents the same shape as Fig. 2(b) and (d), except for another polluted area from north to south to the east of the study area. This method is applied with three classes [Fig. 2(f)]: gray corresponds to oil, white to nonpolluted or less polluted areas, and black an intermediate state between these first two classes. These characteristics concern the surface only, so the area between the two "arms" of the pollution may be polluted at the subsurface level, which cannot be detected by radar.

\section{Use of Synergistic Data}

An ambiguous zone from north to south appears [in black in Fig. 2(f)], which is probably not due to pollution but related to a weak wind area with low radar backscattering due to atmospheric phenomena. This is confirmed by the use of synergistic data [Meteosat visible channel, acquired at $11 \mathrm{~h} 18$ Universal Time Coordinated (UTC)] showing an atmospheric front (clouds) coming from the west, which could be at the location of the north to south line at 10h45 UTC, the time of the SAR image acquisition. Moreover, the ambiguous zone cannot be due to image processing, since SAR images are preprocessed to take into account incidence-angle correction before the analysis (Section IV-B), and in this case, it should appear as a straight line. Another possibility could be that it is related to surface current, but the sea-surface temperature map [MODerate resolution 
TABLE I.

Block Diagram Presenting the Methodology to Follow to Detect OIL SLICK IN RADAR IMAGES: TAKING INTO ACCOUNT WIND-SPEED VALIDITY FOR RADAR MEASUREMENTS, THEN COMPARING THE RADAR CONFIGURATION WITH THE APPROPRIATE ONE IN THE FUNCTION OF THE WIND SPEED, EXtracting Dark Patches by ChOOSING the CoRReCt Method Given THEIR RESPECTIVE ADVANTAGES AND SHORTCOMINGS (NumBER OF METHOD, See Section IV-B), Validating Results With Auxiliary Data That Detect LOOK-Alike and Characterize the Sea State

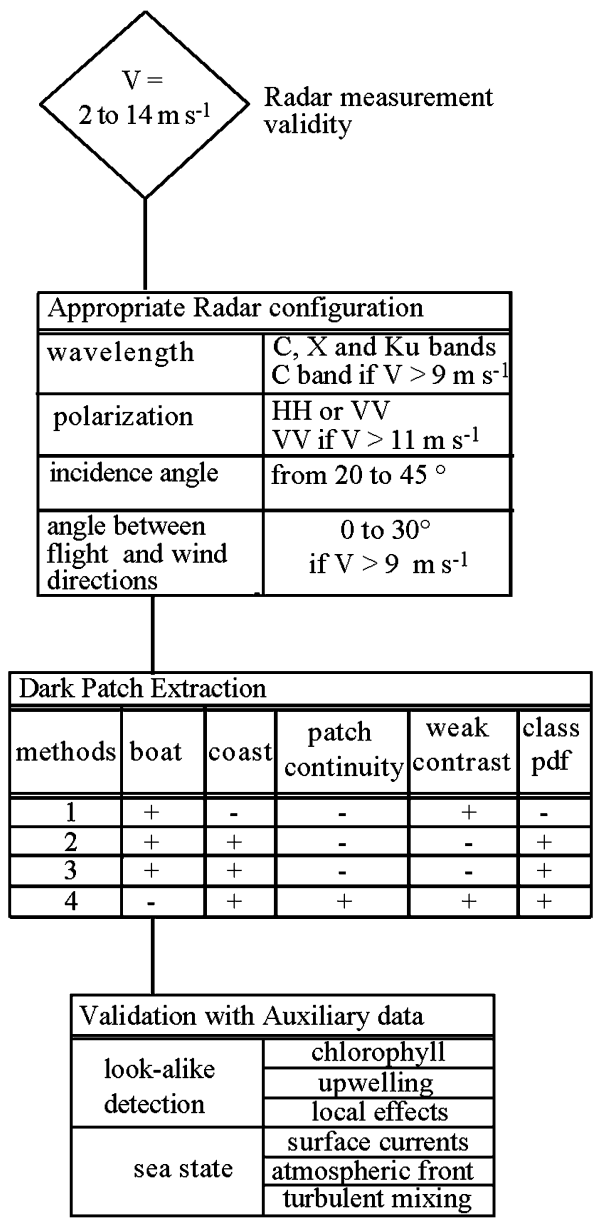

Imaging Spectroradiometer (MODIS)] does not reveal currents. Thus, our conclusion is that this dark vertical area is very likely related to this atmospheric front.

The two polluted "arms" are well detected with the tested methods, except method 2, which is efficient with basic examples only. Method 4 used with three classes is a promising technique providing additional information, as it yields a statistical characterization of each class. The ambiguity of the area between the two polluted "arms" is revealed by the different results of segmentation: Could it be an area where oil is at the subsurface level or a mixture of oil and water? An experts' report is needed in order to process the classification step.

\section{E. Validation}

To test these four algorithms, they were applied on 46 areas of 14 SAR images. The results are compared with aircraft-survey reports. Table I summarizes the advantages and shortcomings of the methods ("dark-patch extraction" part). Method 1 is not applicable without other methods in an operational context since results are very irregular due to several problems. First, shape continuities are not correct; second, the coast may be confused with a detected slick. Method 2 works correctly with coasts or boats in the image, but is not adapted to weak contrast images and to particular slick shapes like straight lines (problem of continuity). Method 3 is interesting since boats and coasts are well detected, but the results present some discontinuities, and the method does not work well with complex images with a weak contrast. Method 4 performs a statistical segmentation, instead of a detection. Although it does not detect boats, it is a supervised method, since the number of classes has to be adapted as a function of the image complexity, as shown in the example in Fig. 2(e) and (f). This provides correct detections if classes are chosen by an operator. One problem is that this novel technique is time consuming.

Simple methods give good results with simple images, but for complex and ambiguous areas, other methods are needed.

\section{ROUTINE APPLICATION FOR SLICK MONITORING}

These slick-detection algorithms were used systematically on 2004 Wide Swath SAR images on the Mediterranean ecological protected zone. The analysis was done in collaboration with CEntre de Documentation de Recherche et d'Expérimentations sur les pollutions accidentelles des eaux (CEDRE) experts for the classification step.

Days and months after the Prestige accident, many slicks were found near the Spanish and French coasts. The difficulties were to find the slicks in difficult atmospheric conditions and with degraded oil. Also, monitoring had to be done to predict the location of slick landings.

\section{A. Data}

Daily maps were available from aircraft surveys linked to oil-spill-drift forecasts (from CEDRE for the French coast and from the Instituto Hidrográfico de Lisboa for the Spanish coast). ESA provided EnviSat and ERS images over the area of the Prestige wreck for several months. Other satellite data were used as synergistic data:

1) SeaWinds on Quick Scatterometer (QuiKSCAT) for surface wind measurements (speed and direction);

2) MODIS on the Terra and Aqua satellites for sea-surface temperature, showing fronts, currents, and upwellings appearing near the coasts;

3) Advanced Very High Resolution Radiometer (AVHRR), Meteosat, for infrared and visible radiations, revealing atmospheric fronts, clouds, storms, etc.;

4) Sea-viewing Wide Field-of-view Sensor (SeaWiFS) for chlorophyll along coasts.

The operational oceanography forecast Mercator was used to understand North Atlantic currents, sea-surface temperature, and salinity vertical profiles. National Oceanic and Atmospheric Administration (NOAA)'s Wave Watch III model provided a sea-state forecast. BOOST implemented the SARTool software, allowing the geolocation-visualization-analysis of several satellite images, bathymetry, and coastline for quick visual comparisons. CMOD algorithm was also used to evaluate wind speed from the SAR images themselves. 


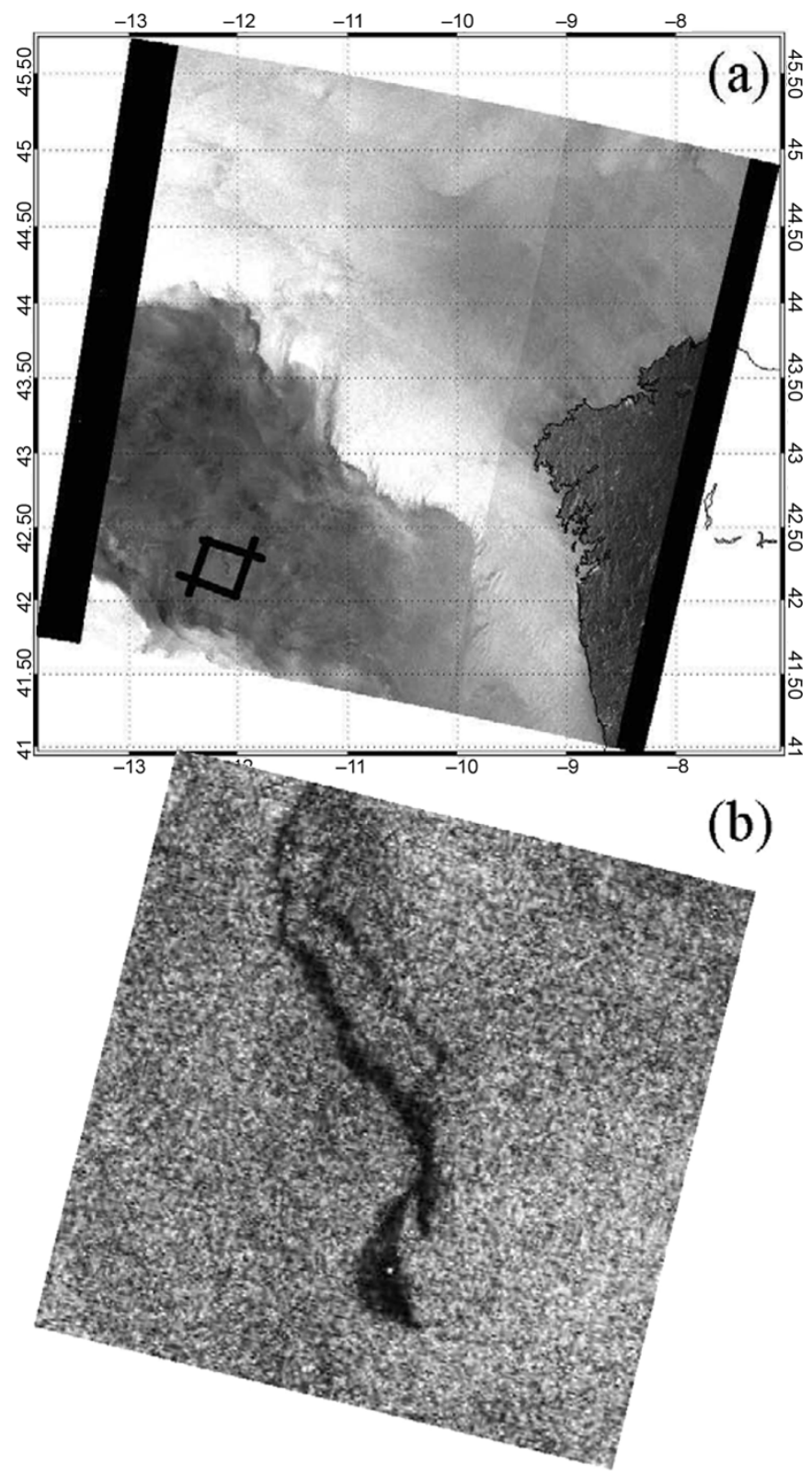

Evolución de la marea negra. Domingo 8 de Diciembre

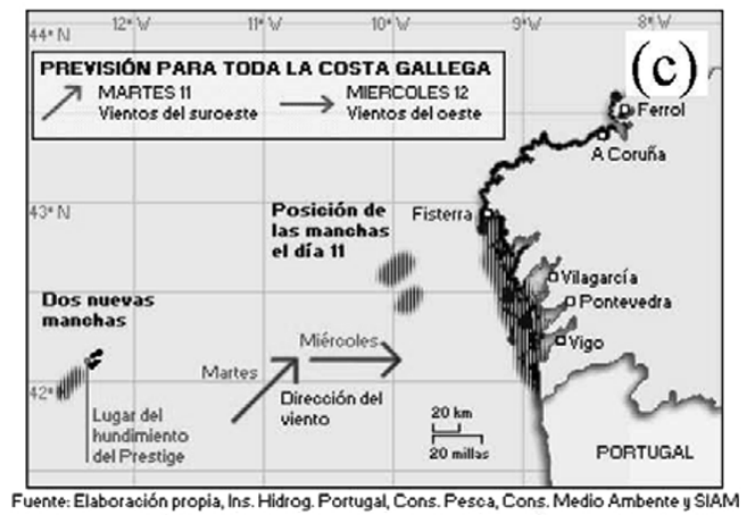

Fig. 3. (a) EnviSat ASAR image, December 9, 2002, 10h53 UTC (wide-swath mode, polarization VV, orbit 4056), surface area: $472 \times 445 \mathrm{~km}$ (Image Courtesy of ESA). The black square shows the study area. (b) Study area (surface area: $19 \times 19 \mathrm{~km}$ ). (c) Oil-pollution observations map from aircraft survey on December 8, 2002, Instituto Hidrográfico, Lisboa (Image courtesy of La Voz de Galicia).

\section{B. SAR-Image Analysis}

Two SAR-image examples were analyzed synergistically to demonstrate the ability of the approach under different conditions.

1) Case of a Slick Detected in a Dark Area: A SAR image from December 9th [Fig. 3(a)] is a good example of the need for synergistic data to understand the high-and-low backscattering levels observed. This image was acquired by the EnviSat satellite at $10 \mathrm{~h} 53 \mathrm{UTC}$.

Conditions on this day are inferred from visible- and infrared-radiation images, which present an atmospheric depression west of Spain, confirmed by SeaWinds data some hours before at $05 \mathrm{~h} 54$ UTC. This depression induces cloudy weather with strong wind-speed gradients, characterized by low-and-high-backscatter-level areas. The low backscatter, in the west of the image, corresponds to the center of the atmospheric depression with counterclockwise-rotating winds, weaker ( 2 to $7 \mathrm{~m} \cdot \mathrm{s}^{-1}$ ) than surroundings where wind speeds can reach more than $15 \mathrm{~m} \cdot \mathrm{s}^{-1}$ (higher backscatter).

Oil spills were observed by aircraft near the coast the day before [Fig. 3(c)], but $15 \mathrm{~m} \cdot \mathrm{s}^{-1}$ is too fast for detection by SAR. Nevertheless, a slick is detected in the area of lower backscattering near the center of the atmospheric depression, where winds are weaker [Fig. 3(b)]. This is a 15-km-long dark patch, with a straight shape (south to north) extending from a round patch (south boundary), where a boat is detected as a very high backscatter value.

In order to classify this slick (natural origin or oil spill), other environmental information has to be known to test our synergistic method. The Wave Watch III model gives only a 1-m significant wave height. In this calm sea condition, the detected slick can thus be natural or an oil spill. Infrared images AVHRR of sea-surface temperature are perturbed by clouds, but still show some fronts, with cold areas in the north of the image and near the detected slick. These cold areas are disconnected from the coast, and are thus, unlikely to be related to upwelling. Using all this information, we can conclude that this slick is very likely an oil spill.

Maps of the Prestige tanker drift, from 13th to 19th November, show the exact location of the wreck (19th), which is exactly the place where the oil spill is detected, 20 days later. Aircraft-observation maps show that the Galician coast is more and more polluted by oil from early December. On December 8th, the oil slick is visible at the location where Prestige sank [Fig. 3(c)] in waters deeper than $3500 \mathrm{~m}$ [45], which means that the tanker continued to leak oil.

This case shows that an oil spill can be detected from SAR images, even when backscatter is strongly perturbed by atmospheric phenomena.

This image reveals the advantages and shortcomings of SAR detection. Spills are well detected in a particular area of the image with weak backscatter; however, no other pollution can be detected near the coast, where winds are too strong.

2) Case of High Wind Speed: The SAR image presented here was acquired by EnviSat over the Prestige tanker oil-drift area on December 2nd at 22h30 UTC [Fig. 4(a)]. The study area is near the coast to the north of the image [Fig. 4(a), (b)], 

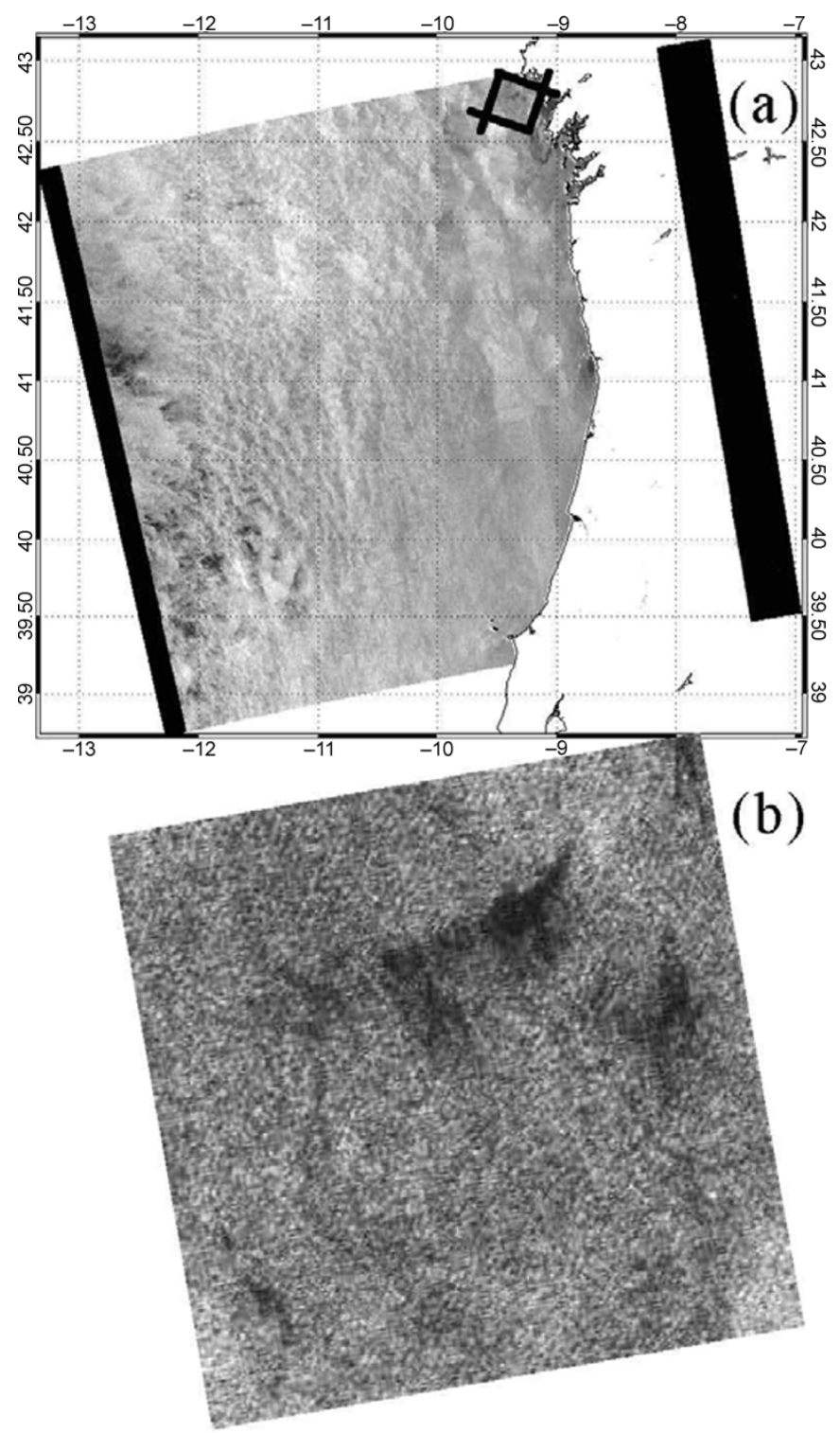

Evolución de la marea negra. Lunes 2 de Diciembre

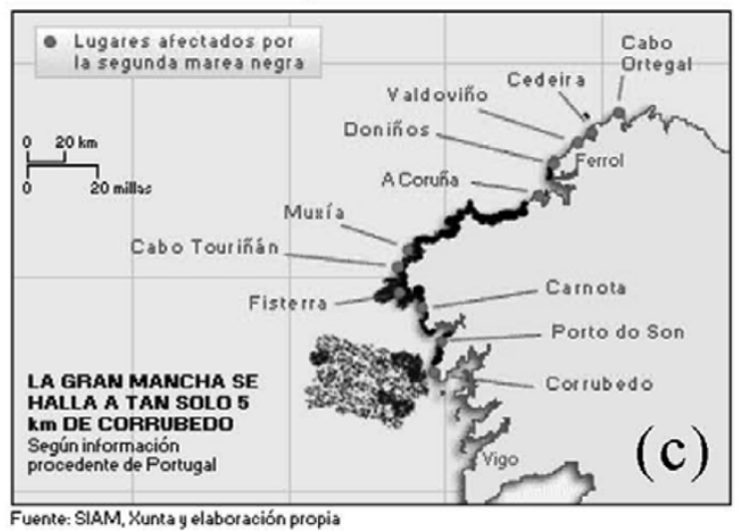

Fig. 4. (a) EnviSat ASAR image, December 2, 2002, 22h30 UTC (wide-swath mode, polarization VV, orbit 3963), surface area: $469 \times 405 \mathrm{~km}$ ESA. The black square shows the study area. (b) Study area (surface area: $19 \times 19 \mathrm{~km}$ ). (c) Oil-pollution observations map from aircraft survey on December 2, 2002, Instituto Hidrográfico, Lisboa La Voz de Galicia.

showing a dark patch with weak contrast, which could be an oil spill or another phenomenon.
On that day, the weather was cloudy (visible-radiation maps), with a strong north/northwesterly flux, confirmed by the direction of wind rolls detected in the image [Fig. 4(a)]. Wind speed can be retrieved directly from the SAR image using the CMOD algorithm, showing values from 5 to over $15 \mathrm{~m} \cdot \mathrm{s}^{-1}$ (12 to 15 $\mathrm{m} \cdot \mathrm{s}^{-1}$ in the study area). Moreover, winds are not offshore, which implies that this black patch does not correspond to weak winds due to an orographic effect. Large waves from the northwest (4-m significant wave height) are present in the area, which are clearly visible in Fig. 4(b). Sea surface-temperature maps show temperature gradients near the coast, but previous information about wind and waves implies that the detected slick does not correspond to cold-water upwelling or any other kind of natural slick because it is not as thick as an oil spill and would be quickly submerged in such conditions.

These synergistic data show that this patch cannot correspond to a natural slick, and thus, must be an oil spill. This conclusion is confirmed by the pollution-observation map on this day [Fig. 4(c)], where coastal pollution is marked, corresponding to the second black tide of the Prestige tanker pollution, which arrived the previous day. It seems that the oil spill [Fig. 4(b)] presents higher contrast on its northern boundary, maybe due to the fact that the wind and waves come from that direction. This is the case on the images that we processed without any explanation. Extensions of the spill to the south are probably due to wind-induced drift.

Wind conditions imply that no slick can be detected where the wind speed is higher than $15 \mathrm{~m} \cdot \mathrm{s}^{-1}$, although aircraft observations detect pollution. This image shows that oil pollution near the coast can be detected by SAR, whereas other spills are hidden in the image, due to wind speed.

\section{CONCLUSION}

Satellite-borne Synthetic Aperture Radar (SAR) is probably one of the best instruments for the study of ocean pollution. Its all-time all-weather availability is a decisive advantage for ocean monitoring compared with optical measurements. SAR allows instantaneous coverage of areas as large as $500 \times 500$ $\mathrm{km}$ (wide-swath mode on EnviSat) with high-resolution data. However, SAR imaging of slicks can still be limited by atmospheric and oceanic conditions.

A methodology for SAR-image analysis is summarized in Table I. The main limitations of SAR measurements are sea state linked with wind speed. If the wind speed remains between 2 to $14 \mathrm{~m} \cdot \mathrm{s}^{-1}$, ocean-surface radar measurements can be usable if the radar configuration is adapted to the wind-speed value. The image analysis essentially consists of the detection of low radar backscatter (shown in dark by convention) in the ocean scene. Detection algorithms should be adapted in the function of the image parameters and complexity (statistics, contrast, presence of boat, etc.).

The classification step is greatly facilitated by auxiliary data, including surface winds (quantitative from scatterometers or qualitative from visible geostationary satellite pictures of clouds), sea-surface temperature, sea state, and surface currents. These information are becoming increasingly available in near-real time, thanks to the efforts of space agencies, 
meteorological organizations, the Global Ocean Observing System (GOOS), and its regional subsystems. Determining the nature of the slick is possible from the knowledge of some local phenomena that appear as pollution on radar images but are look-alikes. The synergistic data used in the present paper were available free of charge on the Internet, some within a few hours of acquisition, others in a short-delay mode ( 1 or 2 days after acquisition).

The application of this methodology to the Prestige oil spill demonstrates that the knowledge of environmental conditions, such as wind speed and direction, wave height, sea-surface temperature, and currents can explain the origin of slicks in most cases, as confirmed by aerial surveys. This approach is limited by the radar configuration, since the reliability of the radar acquisition depends on the knowledge of the wind speed. Nevertheless its estimation is difficult to assess. Furthermore, this approach is limited by the choice of detection algorithm, and then, to the availability of the synergistic data.

The goal of such an analysis is to make a presumption that a detected slick is due to pollution. Such an approach should be the basis of future operational monitoring systems for the marine environment, using the regular passes of present and soon-to-be-launched satellites. The real usefulness of these systems will crucially depend on sensor reactivity and data delivery and a partially automated processing of the SAR images, possibly based on the algorithms described here. In-time processing is essential in the decision process, in order to direct aircraft or ships toward recent illegal discharges and to organize adequate responses to combat large oil spills.

\section{ACKNOWLEDGMENT}

The authors would like to thank ESA for the ERS, EnviSat, and Meteosat images; NOAA and NASA for SeaWinds, SeaWIFS, AVHRR, MODIS data, and for the Wave Watch III model; Mercator Project Team for sea-current data, and CEDRE (http://www.le-cedre.fr), and La voz de Galicia (http://www.lavozdegalicia.es) for maps. The authors also thank V. Kerbaol (BOOST, Plouzané, France, http://www.boost-technologies.com) for the development of the SARTool software and F. Ardhuin for relevant remarks.

\section{REFERENCES}

[1] J. S. Scott, "Ocean surface slicks-Pollution, productivity, climate and life-saving," in IEEE Proc. Int. Geoscience and Remote Sensing Symp. (IGARSS), vol. 3, Hamburg, Germany, Jun. 28-Jul. 2 1999, pp. $1463-1468$.

[2] H. Hühnerfuss and W. D. Garrett, "Experimental sea slicks: Their practical applications and utilization for basic studies of air-sea interactions," J. Geophys. Res., vol. 86, no. C1, pp. 439-447, Jan. 1981.

[3] J. S. Scott, "The historical development of theories of wave-calming using oil," Hist. Technol., vol. 3, pp. 163-186, 1978.

[4] J. Lu, H. Lim, S. C. Liew, M. Bao, and L. K. Kwoh, "Oil pollution statistics in Southeast Asian waters compiled from ERS SAR imagery," Earth Obs. Q., vol. 61, pp. 13-17, Feb. 1999.

[5] P. Pavlakis, D. Tarchi, and A. J. Sieber, "On the monitoring of illicit vessel discharges using spaceborne SAR remote sensing-A reconnaissance study in the Mediterranean sea," Ann. Telecommun., vol. 56, no. 11-12, pp. 700-718, 2001.

[6] P. Pavlakis, A. J. Sieber, and S. Alexandry, "Monitoring oil-spill pollution in the Mediterranean with ERS SAR," Earth Obs. Q., vol. 52, 1994.
[7] M. Gade and S. Ufermann, "Using ERS-2 SAR images for routine observation of marine pollution in European coastal waters," in IEEE Proc. Int. Geoscience and Remote Sensing Symp. (IGARSS), Seattle, WA, Jul. 6-10, 1998, pp. 757-759.

[8] A. H. S. Solberg, G. Storvik, R. Solberg, and E. Volden, "Automatic detection of oil spills in ERS SAR images," IEEE Trans. Geosci. Remote Sens. E, vol. 37, no. 4, pp. 1916-1924, Jul. 1999.

[9] B. Franklin, "On the stilling of waves by means of oil," Philos. Trans., vol. 64 , pp. 445-460, 1774.

[10] C. Marangoni, "Sul principio della viscositá superficiale dei liquidi stabilito," Nuevo Cimento, ser. 2, no. 5/6, pp. 239-273, 1872.

[11] W. Alpers and H. Hühnerfuss, "Radar signatures of oil films floating on the sea surface and the Marangoni effect," J. Geophys. Res., vol. 93, no. C4, pp. 3642-3648, Apr. 1988.

[12] - "The damping of ocean waves by surface films: A new look at an old problem," J. Geophys. Res., vol. 94, no. C5, pp. 6251-6265, May 1989.

[13] H. Hühnerfuss, W. Alpers, and W. L. Jones, "Measurements at $13.9 \mathrm{GHz}$ of the radar backscattering cross section of the North Sea covered with an artificial surface film," Radio Sci., vol. 13, no. 6, pp.979-983, Nov.-Dec. 1978.

[14] H. Hühnerfuss, W. Alpers, P. A. Lange, and W. Walter, "Attenuation of wind waves by artificial surface films of different chemical structures," Geophys. Res. Lett., vol. 8, no. 11, pp. 1184-1186, 1981.

[15] H. Hühnerfuss, W. Alpers, A. Cross, W. D. Garrett, W. C. Keller, P. A. Lange, W. J. Plant, F. Schlude, and D. L. Schuler, "The modification of $\mathrm{X}$ and L-band radar signals by monomolecular sea slicks," J. Geophys. Res., vol. 88, no. C14, pp. 9817-9822, Nov. 1983.

[16] H. Hühnerfuss, W. Alpers, W. D. Garrett, P. A. Lange, and S. Stolte, "Attenuation of capillary and gravity waves at sea by monomolecular organic surface films," J. Geophys. Res., vol. 88, no. C14, pp. 9809-9816, Nov. 1983.

[17] V. Wismann, "Radar signatures of mineral oil spills measured by an airborne multi-frequency radar and the ERS-1 SAR," in IEEE Proc. Int. Geoscience and Remote Sensing Symp. (IGARSS), Tokyo, Japan, Aug. 18-21, 1993, pp. 940-942.

[18] P. Pavlakis, A. Sieber, and S. Alexandry, "On the optimization of spaceborne SAR capacity in oil spill detection and the related hydrodynamic phenomena," Spill Sci. Technol. Bull., vol. 3, no. 1/2, pp. 33-40, 1996.

[19] M. Gade, W. Alpers, H. Hühnerfuss, H. Masuko, and T. Kobayashi, "Imaging of biogenic and anthropogenic ocean surface films by the multifrequency/multipolarization SIR-C/X-SAR," J. Geophys. Res., vol. 103, no. C9, pp. 18851-18866, Aug. 1998.

[20] H. Hühnerfuss, A. Gericke, W. Alpers, R. Theis, V. Wismann, and P. A. Lange, "Classification of sea slicks by multifrequency radar techniques: New chemical insights and their geophysical implications," J. Geophys. Res., vol. 99, no. C5, pp. 9835-9845, May 1994.

[21] V. Wismann, M. Gade, W. Alpers, and H. Hühnerfuss, "Radar signatures of marine mineral oil spills measured by an airborne multi-frequency radar," Int. J. Remote Sens., vol. 19, no. 18, pp. 3607-3623, Dec. 1998.

[22] J. W. Johnson and W. F. Croswell, "Characteristics of $13.9 \mathrm{GHz}$ radar scattering from oil films at the sea surface," Radio Sci., vol. 17, no. 3, pp. 611-617, 1982.

[23] W. Alpers, V. Wismann, R. Theis, H. Hühnerfuss, N. Bartsch, J. Moreira, and J. D. Lyden, "The damping of ocean surface waves by monomolecular sea slicks measured by airborne multi-frequency radars during the SAXON-FPN experiment," in IEEE Proc. Int. Geoscience and Remote Sensing Symp. (IGARSS), vol. 4, Helsinki, Finland, Jun. 3-6, 1991, pp. 1987-1990.

[24] G. Franceschetti, A. Iodice, D. Riccio, G. Ruello, and R. Siviero, "SAR raw signal simulation of oil slicks in ocean environment," IEEE Trans. Geosci. Remote Sens. E, vol. 40, no. 9, pp. 1935-1949, Sep. 2002.

[25] H. A. Espedal, O. M. Johannessen, and J. Knulst, "Natural films in coastal waters," in IEEE Proc. Int. Geoscience and Remote Sensing Symp. (IGARSS), Florence, Italy, Jul. 10-14, 1995, pp. 2106-2108.

[26] P. Trivero, B. Fiscella, F. Gomez, and P. Pavese, "SAR detection and characterization of sea surface slicks," Int. J. Remote Sens., vol. 19, no. 3, pp. 543-548, Feb. 1998.

[27] K. P. Singh, A. L. Gray, R. K. Hawkins, and R. A. O'Neil, "The influence of surface oil on C- and Ku-band ocean backscatter," IEEE Trans. Geosci. Remote Sens. E, vol. GE-24, no. 5, pp. 738-744, Sep. 1986.

[28] H. Masuko, T. Kobayashi, K. Okamoto, and W. Alpers, "Observation of artificial slicks with SIR-C/X-SAR around Japan," in IEEE Proc. Int. Geoscience and Remote Sensing Symp. (IGARSS), vol. 1, Florence, Italy, Jul. 10-14, 1995, pp. 227-229.

[29] G. R. Valenzuela, "Theories for the interaction of electromagnetic and oceanic waves-A review," Boundary-Layer Meteorol., vol. 13, pp. 61-85, 1978. 
[30] K. Krishen, "Detection of oil spills using a $13.3 \mathrm{GHz}$ radar scatterometer," J. Geophys. Res., vol. 78, no. 12, pp. 1952-1963, Apr. 1973.

[31] H. Hühnerfuss, W. D. Garrett, and F. E. Hoge, "The discrimination between crude-oil spills and monomolecular sea slicks by an airborne lidar," Int. J. Remote Sens., vol. 7, no. 1, pp. 137-150, 1986.

[32] H. Hühnerfuss, W. Alpers, and K. Richter, "Discrimination between crude-oil spills and monomolecular sea slicks by airborne radar and infrared radiometer-Possibilities and limitations," Int. J. Remote Sens., vol. 7, no. 8, pp. 1001-1013, Aug. 1986

[33] M. Gade, W. Alpers, H. Hühnerfuss, V. Wismann, and P. Lange, "On the reduction of the radar backscatter by oceanic surface films: Scatterometer measurements and their theoretical interpretation," Remote Sens. Environ., vol. 66, no. 1, pp. 52-70, Oct. 1998.

[34] M. Gade, J. Scholz, and C. Von Viebahn, "On the detectability of marine oil pollution in European marginal waters by means of ERS SAR imagery," in IEEE Proc. Int. Geoscience and Remote Sensing Symp. (IGARSS), vol. 6, Honolulu, HI, Jul. 24-28, 2000, pp. 2510-2512.

[35] P. Lombardo, D. Conte, and A. Morelli, "Comparison of optimised processors for the detection and segmentation of oil slicks with polarimetric SAR images," in IEEE Proc. Int. Geoscience and Remote Sensing Symp. (IGARSS), vol. 7, Honolulu, HI, Jul. 24-28, 2000, pp. 2963-2965.

[36] K. W. Bjerde, A. H. Solberg, and R. Solberg, "Oil spill detection in SAR imagery," in IEEE Proc. Int. Geoscience and Remote Sensing Symp. (IGARSS), vol. 3, Tokyo, Japan, Aug. 18-21, 1993, pp. 943-945.

[37] H. Espedal, "Detection of oil spill and natural film in the marine environment by spaceborne SAR," in IEEE Proc. Int. Geoscience and Remote Sensing Symp. (IGARSS), vol. 3, Hamburg, Germany, Jun. 28-Jul. 2 1999, pp. 1478-1480

[38] M. Bertacca, F. Berizzi, E. Dalle Mese, and A. Capria, "A FARIMAbased analysis for wind falls and oil slicks discrimination in sea SAR imagery," in IEEE Proc. Int. Geoscience and Remote Sensing Symp. (IGARSS), Anchorage, AK, Sep. 20-24, 2004.

[39] F. Frate, A. Petrocchi, J. Lichtenegger, and G. Calabresi, "Neural networks for oil spill detection using ERS-SAR data," IEEE Trans. Geosci. Remote Sens. E, vol. 38, no. 5, pp. 2282-2287, Sep. 2000.

[40] B. Fiscella, A. Giancaspro, F. Nirchio, P. Pavese, and P. Trivero, "Oil spill detection using marine SAR images," Int. J. Remote Sens., vol. 21, no. 18, pp. 3561-3566, Dec. 2000.

[41] C. Brekke and A. H. S. Solberg, "Oil spill detection by satellite remote sensing," Remote Sens. Environ., vol. 95, no. 1, pp. 1-13, Mar. 2005

[42] J. Lichtenegger, "Using ERS-1 SAR images for oil spill surveillance," Earth Obs. Q., vol. 44, pp. 7-10, Jun. 1994.

[43] Y. Quilfen, B. Chapron, T. Elfouhaily, K. Katsaros, and J. Tournadre, "Observation of tropical cyclones by high resolution scatterometry," $J$. Geophys. Res., vol. 103, no. C4, pp. 7767-7786, Apr. 1998.

[44] G. Mercier, S. Derrode, W. Pieczynski, J.-M. Le Caillec, and R. Garello, "Multiscale oil slick segmentation with Markov chain model," in IEEE Proc. Int. Geoscience and Remote Sensing Symp. (IGARSS), vol. 6, Toulouse, France, Jul. 21-25, 2003, pp. 3501-3503.

[45] V. Kondrachoff-Samuel and F. Parthiot, "The use of satellite radar to improve the surveillance of oil pollution over large areas," in Proc. Radar and Marine Environment Workshop, Brest, France, Jun. 10, 2003.

[46] C. Rousseau, "Accident du Prestige, 13 Novembre 2002, Cap Finisterre (Galice), les premières opérations," Bulletin d'information du CEDRE, no. 18,2003

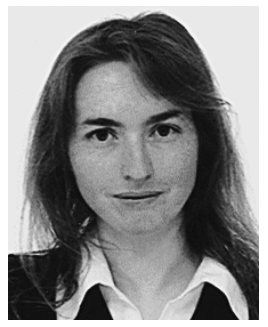

Fanny Girard-Ardhuin (M'03) was born in 1975. She received the $\mathrm{Ph} . \mathrm{D}$. degree in radar meteorology at the Laboratoire d'Aérologie, Toulouse, France, in 2001. Her thesis was focused on the study of the atmospheric boundary layer using a wind-profiler radar with a radio-acoustic sounding system.

She spent 1 year at the Ecole Nationale Supérieure des Télécommunications de Bretagne (ENST Bretagne), Brest, France, in 2003, working on synthetic aperture radar (SAR) images for the European project MARine SAR Analysis and Interpretation System (MARSAIS), including oil-spill detection. She joined Brest Operational Observation Systems and Technologies (BOOST), Plouzané, France, to test oil-slick-detection algorithms applied on SAR images. She is currently working as a Postdoctoral Research Associate at the Institut Français de Recherche pour l'Exploitation de la MER (IFREMER), Plouzané, France, where her main research interest lies in sea-ice observation from active and passive satellites.

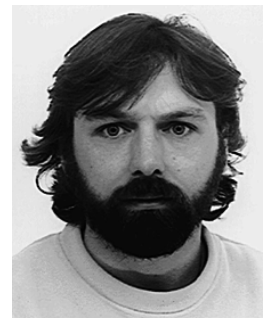

Grégoire Mercier (M'02) was born in France in 1971. He received the Engineering Degree from Institut National des Télécommunications (INT), Évry, France, in 1993, and the Ph.D. degree from the University of Rennes, France, in 1999.

Since 1999, he has been with the Ecole Nationale Supérieure des Télécommunications de Bretagne (ENST Bretagne), Brest, France, where he is currently an Associate Professor in the Image and Information Processing Department. His research interests are in remote-sensing image compression and segmentation, especially in hyperspectral and synthetic aperture radar (SAR). His research is focused on change detection and combating pollution.

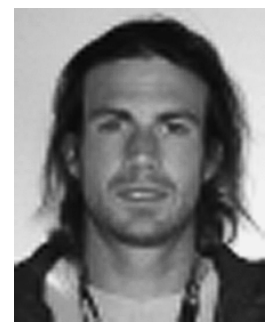

Fabrice Collard was born in 1973 . He graduated from Ecole Centrale de Lyon, France, in 1996, where he studied off-shore engineering. In 2000, he received the Ph.D. degree in oceanography and meteorology environment. His thesis was focused on the three-dimensional aspect of the wind-wave field.

He spent 2 years working on HF radars as a Postdoctoral Research Associate at Rosenstiel School of Marine and Atmospheric Science (RSMAS), Miami, FL. He is currently working at Brest Operational Observation Systems and Technologies (BOOST), Plouzané, France, on the validation of the synthetic aperture radar (SAR) of Environment Satellite (EnviSat).

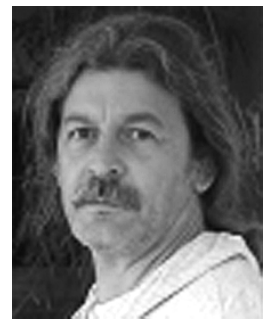

René Garello (M'85-SM'96) received the Ph.D. degree in signal processing at the Institut National Polytechnique de Grenoble (INPG), France, in 1981.

From 1982 to 1984, he worked as a Research Associate at Aeronomy Lab, National Oceanic and Atmospheric Administration (NOAA), Boulder, CO. He joined the Ecole Nationale Supérieure des Télécommunications de Bretagne (ENST Bretagne), Brest, France, in 1985. Since 1988, he has been a Professor at ENST Bretagne, in the field of signal processing and image processing. His main research interests lie in remote sensing, two-dimensional signal processing, and statistical and spectral analysis applied to ocean-surface-features detection and characterization.

Prof. Garello started a French Institute of Electrical and Electronics Engineers (IEEE)/Oceanic Engineering Society (OES) Chapter in 1993, of which he became Chairman in 1995. Since 1993, he has been involved in the organization of the Student Poster Competition for the OCEANS series of conferences For OCEANS'98, held in Nice, France, he was Cochair of the Technical Program Committee, Chair of the Publicity Committee, and Chair of the Student Poster Competition. Since 1997, he has been the Associate Editor for Region 8 of the IEEE JOURNAL OF OCEANIC ENGINEERING, and he was elected to the OES Adcom Committee in 1998. He is also an active member of the IEEE Geoscience and Remote Sensing Society. 